\title{
PENGARUH BERBAGAI KOMPOSISI DOSIS KOMPOS UNPAD DAN PUPUK BUATAN TERHADAP PERTUMBUHAN DAN HASIL TANAMAN JAGUNG MANIS (Zea mays saccharata L.) VARIETAS BONANZA
}

\section{The Effects of Various Doses of The Composition UNPAD Compost and Fertilizers on Growth and Yield of Sweet Corn (Zea mays) Varieties Bonanza}

\author{
Yayan Sumekar ${ }^{1}$ \\ 1Departemen Budidaya Pertanian Fakultas Pertanian \\ Universitas Padjajaran \\ E-mail : yayan.sumekar@gmail.com
}

\begin{abstract}
Abstrak
Penelitian bertujuan untuk mengetahui komposisi dosis pupuk kompos UNPAD dan pupuk buatan terhadap pertumbuhan dan hasil Jagung manis. Rancangan percobaan yang digunakan adalah Rancangan Acak Kelompok dengan terdiri dari tujuh perlakuan, yaitu : $A=10 \mathrm{~kg} / \mathrm{ha}$ kompos $+5 \mathrm{cc} / \mathrm{L} P O C+$ pupuk buatan ( $0 \mathrm{~kg} / \mathrm{ha}$ Urea, $0 \mathrm{~kg} / \mathrm{ha} \mathrm{SP-36,} 0 \mathrm{~kg} / \mathrm{ha} \mathrm{KCl}), B=8 \mathrm{~kg} / \mathrm{ha}$ kompos + $5 \mathrm{cc} / \mathrm{L} \mathrm{POC} \mathrm{+} \mathrm{pupuk} \mathrm{buatan}(60 \mathrm{~kg} / \mathrm{ha}$ Urea, $20 \mathrm{~kg} / \mathrm{ha}$ SP-36, $20 \mathrm{~kg} / \mathrm{ha} \mathrm{KCl}), \mathrm{C}=6 \mathrm{~kg} / \mathrm{ha}$ kompos $+5 \mathrm{cc} / \mathrm{L}$ POC +pupuk buatan (120 kg/ha Urea, $40 \mathrm{~kg} / \mathrm{ha} \mathrm{SP}-36,40 \mathrm{~kg} / \mathrm{ha} \mathrm{KCl})$, $\mathrm{D}=4 \mathrm{~kg} / \mathrm{ha}$ kompos $+5 \mathrm{cc} / \mathrm{L} \mathrm{POC}+$ pupuk buatan $(180 \mathrm{~kg} / \mathrm{ha}$ Urea, $60 \mathrm{~kg} / \mathrm{ha} \mathrm{SP}-36,60 \mathrm{~kg} / \mathrm{ha} \mathrm{KCl}), \mathrm{E}=2 \mathrm{~kg} / \mathrm{ha} \mathrm{kompos}+5$ cc/L POC + pupuk buatan $(240 \mathrm{~kg} / \mathrm{ha}$ Urea, $80 \mathrm{~kg} / \mathrm{ha}$ SP-36, 80 $\mathrm{kg} / \mathrm{ha} \mathrm{KCl}), \mathrm{F}=0 \mathrm{~kg} / \mathrm{ha}$ kompos $+5 \mathrm{cc} / \mathrm{L} \mathrm{POC}+$ pupuk buatan

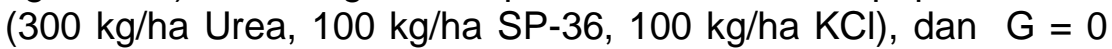
$\mathrm{kg} / \mathrm{ha}$ kompos + $0 \mathrm{cc} / \mathrm{L} \mathrm{POC}+$ pupuk buatan $(300 \mathrm{~kg} / \mathrm{ha}$ Urea, $100 \mathrm{kgs} / \mathrm{ha}$ SP-36, $100 \mathrm{~kg} / \mathrm{ha} \mathrm{KCl}$ ). Hasil percobaan menunjukkan komposisi dosis kompos UNPAD dan pupuk buatan berpengaruh terhadap pertumbuhan dan hasil tanaman jagung manis (Zea mays saccharata I.) varietas Bonanza. Komposisi dosis Perlakuan 4 ton kompos/ha $+5 \mathrm{cc} / \mathrm{l} \mathrm{POC}+180$ $\mathrm{kg}$ Urea/ha, $60 \mathrm{~kg} \mathrm{SP}-36 / \mathrm{ha}, 60 \mathrm{~kg} \mathrm{KCl} / \mathrm{ha} 3$ berpengaruh paling baik terhadap tinggi tanaman, diameter batang, jumlah daun per tanaman, panjang tongkol, diameter tongkol, bobot tongkol berkelobot, bobot tongkol tanpa kelobot, dan hasil tongkol per plot.
\end{abstract}

Kata kunci : kompos UNPAD, pupuk buatan, jagung manis 


\begin{abstract}
The experiment was conducted the study the effect of various composition of dose of compost unpad and brand fertilize on growth and yield of sweet maize crop (Zeamays saccharata L.) cv. BonanzaExperiment design used was a Randomized Block Design with that is : $A=10 \mathrm{~kg} / \mathrm{ha}$ compost $+5 \mathrm{cc} / \mathrm{L}$ organic foliar

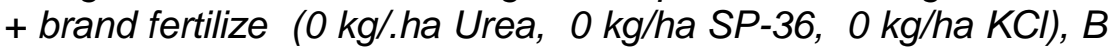
$=8 \mathrm{~kg} / \mathrm{ha}$ compost $+5 \mathrm{cc} / \mathrm{L}$ organic foliar + brand fertilize $(60$ kgs/.ha Urea, $20 \mathrm{kgs} / \mathrm{ha} S P-36,20 \mathrm{kgs} / \mathrm{ha} \mathrm{KCl}), C=6 \mathrm{kgs} / \mathrm{ha}$ compost + $5 \mathrm{cc} / \mathrm{L}$ organic foliar + brand fertilize $(120 \mathrm{kgs} / \mathrm{ha}$ Urea, $40 \mathrm{kgs} / \mathrm{ha} S P-36,40 \mathrm{kgs} / \mathrm{ha} \mathrm{KCl}), D=4 \mathrm{kgs} / \mathrm{ha}$ compost + $5 \mathrm{cc} / \mathrm{L}$ organic foliar + brand fertilize $(180 \mathrm{kgs} / \mathrm{ha}$ Urea, 60

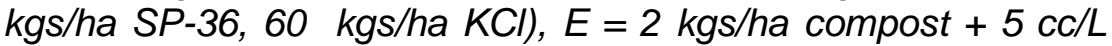
$P O C$ + brand fertilize (240 kg/.ha Urea, $80 \mathrm{~kg} / \mathrm{ha} S P-36,80$ $\mathrm{kgs} / \mathrm{ha} \mathrm{KCl}), F=0 \mathrm{~kg} / \mathrm{ha}$ compost $+5 \mathrm{cc} / \mathrm{L}$ organic foliar + brand fertilize (300 kgs/.ha Urea, $100 \mathrm{kgs} / \mathrm{ha} S P-36,100 \mathrm{kgs} / \mathrm{ha} \mathrm{KCl})$,, dan $G=0 \mathrm{kgs} / \mathrm{ha}$ compost + $0 \mathrm{cc} / \mathrm{L}$ organic foliar + brand fertilize (300 kgs/ha Urea, $100 \mathrm{kgs} / \mathrm{ha} \mathrm{SP}-36,100 \mathrm{kgs} / \mathrm{ha} \mathrm{KCl}$ ). The experiment showed that the composition dose of compost Unpad and brand fertilize to effect on growth and yield sweet cor (Zea mays saccharata L.) cv. Bonanza. Composition dose of 4 tons compost/ha $+5 \mathrm{cc} / \mathrm{l}$ organic foliar $+180 \mathrm{kgs}$ Urea/ha, $60 \mathrm{kgs}$ $S P-36 / \mathrm{ha}, 60 \mathrm{kgs} \mathrm{KCl/ha}$ ther best affect on height of plant, number of leaf per plant, diameter og crop bar, length of cob, diameter of cob, weight of cob, and yield per plot.
\end{abstract}

Keywords : Compost UNPAD, Brand Fertilize, Sweet Maize Crop

\section{PENDAHULUAN}

Jagung manis (Zea mays var. saccarata) adalah tanaman pangan yang sangat bermanfaat bagi kehidupan manusia ataupun hewan. Jagung merupakan makanan pokok kedua setelah padi di Indonesia. Sedangkan, berdasarkan urutan bahan makanan pokok di dunia, jagung menduduki urutan ketiga setelah gandum dan padi. Tanaman jagung hingga kini dimanfaatkan

oleh masyarakat dalam berbagai bentuk penyajian, seperti : tepung jagung (maizena), minyak jagung, bahan pangan, serta sebagai pakan ternak dan lainlainnya. Khusus jagung manis (sweet corn), sangat disukai dalam bentuk jagung rebus atau bakar (Derna, 2007).

Produksi jagung manis di Indonesia pada tahun 2013 mengalami 
penurunan dibandingkan dengan produksi jagung manis pada tahun 2012. Produksi jagung manis pada tahun 2013 adalah 18.506.287 ton sedangkan pada tahun 2012 adalah 19.377.030 ton (Badan Pusat Statistik, 2013).

Penyebab terjadinya penurunan produksi jagung manis disebabkan adanya alih fungsi lahan, menurunnya kesuburan tanah, pemupukan yang tidak seimbang, adanya penyakit bulai yang disebabkan oleh jamur Peronosclerospora maydis, dan penggunaan pestisida yang tidak sesuai dengan anjuran dan terus menerus, sehingga menyebabkan kekebalan terhadap OPT yang menyerang tanaman jagung.

Solusi atau cara yang bisa diterapkan untuk meningkatkan produksi jagung manis diantaranya mengoptimalkan lahan yang masih tersedia, penggunaan pupuk organik dan anorganik secara berimbang untuk meningkatkan kesuburan tanah, pencegahan hama penyakit dengan menggunakan pestisida sesuai anjuran.

$$
\text { Salah satu aspek }
$$
yang mempengaruhi jumlah produksi jagung manis adalah produktivitas. Ada empat hal penting yang harus diperhatikan dalam meningkatkan produktivitas tanaman, yaitu: pengairan, pemupukan, pengendalian hama, dan penggunaan varietas tanaman yang baik. Upaya yang dapat ditempuh untuk mendapatkan varietas tanaman yang memiliki potensi produktivitas yang tinggi dengan kualitas hasil yang baik dapat ditempuh melalui program pemuliaan tanaman.

$$
\text { Hasil penelitian }
$$

Pusat Tanah dan Agroklimat Bogor mengungkapkan bahwa sebagian besar tanah pertanian di Indonesia mengalami penurunan kesuburan akibat penggunaan pupuk kimia, sehingga produktivitasnya menurun. Memburuknya kondisi tanah, menyebabkan pemupukan harus dilakukan secara terpadu dengan memanfaatkan berbagai jenis pupuk yaitu pupuk anorganik, organik dan hayati secara bersamasama. Selain menyediakan hara pupuk organik juga berperan sebagai sumber energi bagi organisme tanah dan memperbaiki sifat fisik tanah serta meningkatkan efisiensi pupuk anorganik.

Salah satu pupuk organik yang dapat digunakan dalam upaya meningkatkan hasil tanaman jagung adalah pupuk organik yang berasal dari 
kompos (pupuk organik padat) dan pupuk organik cair. Pemakaian pupuk organik dalam budidaya tanaman merupakan satu hal yang sangat diperlukan. Selain untuk meningkatkan kuantitas hasil, juga pupuk kotoran domba dapat memperbaiki dan mempertahankan tingkat kesuburan tanah. Kandungan hara dalam pupuk organik relatif rendah dibandingkan dengan pupuk anorganik, tetapi pupuk kompos mempunyai beberapa keistimewaan, antara lain dapat memperbaiki sifat-sifat fisik tanah, kimia, dan biologi tanah, sehingga dapat menjaga kesuburan tanah, namun demikian pemberian pupuk organik harus disesuaikan dengan dosis dan komposisinya, sehingga kersediaan unsur hara dalam tanah dalam keadaan seimbang untuk menyuplai kebutuhan tanaman.

\section{METODOLOGI}

\section{Lokasi dan Waktu Penelitian}

dengan menggunakan metode eksperimen melalui percobaan di lapangan. Percobaan ini dilaksanakan di desa Padaasih kecamatan Pasirwangi kabupaten Garut yang terletak di Balai Penyuluhan Pertanian, Perikanan dan Kehutanan (BP3K) yang terletak pada ketinggian 800 $\mathrm{m}$ dpl.dengan jenis tanah Andosol dengan curah hujan rata-rata setiap tahun 385 $\mathrm{mm}$. Waktu percobaan dimulai dari bulan Mei 2015 sampai Agustus 2015.

\section{Bahan dan Alat Penelitian Bahan percobaan} meliputi pupuk kompos dan Pupuk Organik Cair (POC) hasil produksi UPT Lingkungan Kampus Universitas Padjajaran. Sedangkan varietas jagung manis yang digunakan adalah varietas Bonanza, pupuk dan bahan pemeliharaan lain yang digunakan yaitu Urea, SP 36 , dan $\mathrm{KCl}$ dengan dosis sesuai dengan perlakuan percobaan.

Alat yang digunakan dalam percobaan ini meliputi alat pengolah tanah seperti cangkul, sprayer (alat penyemprot), gelas ukur (2000 cc), timbangan, kamera dan alat tulis.

\section{Metodologi Penelitian}

Rancangan yang digunakan dalam percobaan ini adalah Rancangan Acak Kelompok (RAK), terdiri atas tujuh perlakuan yang diulang empat kali. Perlakuan yang dicoba adalah sebagai berikut : 
Tabel 1. Perlakuan

\begin{tabular}{cccc}
\hline \multirow{2}{*}{ Kode } & \multicolumn{4}{c}{ Perlakuan } \\
\cline { 2 - 4 } & Kompos (ton/ha) & POC (cc/l) & PupukBuatan (kg/ha) \\
\hline A & 10 & 5 & 0 \\
B & 8 & 5 & 60 Urea, 20 SP 36,20 KCl \\
C & 6 & 5 & 120 Urea, 40 SP 36, 40 KCl \\
D & 4 & 5 & 180 Urea, 60 SP 36, 60 KCl \\
E & 2 & 5 & 240 Urea, 80 SP 36, $80 \mathrm{KCl}$ \\
F & 0 & 5 & 300 Urea, 100 SP 36, 100 KCl \\
G & 0 & 0 & 300 Urea, 100 SP 36, 100 KCl \\
\hline
\end{tabular}

Keterangan: Perlakuan $\mathrm{G}$ adalah perlakuan kontrol.

HASIL

\section{DAN}

\section{PEMBAHASAN}

\section{1) Tinggi tanaman}

Data hasil pengamatan ratarata tinggi tanaman terdapat pada Tabel 2.

Tabel 2. Tinggi Tanaman

\begin{tabular}{|c|c|c|c|c|c|c|c|c|}
\hline \multirow{2}{*}{ Perlakuan } & \multicolumn{8}{|c|}{ Rata-rata Tinggi Tanaman (cm) } \\
\hline & $2 \mathrm{MS}$ & & $4 \mathrm{Ms}$ & & $6 \mathrm{MS}$ & & $8 \mathrm{MS}$ & \\
\hline A & 42,88 & a & 82,85 & $\mathrm{a}$ & 172,75 & a & 190,00 & $\mathrm{a}$ \\
\hline B & 45,49 & a & 91,98 & a & 180,23 & a & 197,38 & $a b$ \\
\hline $\mathrm{C}$ & 36,68 & a & 87,70 & a & 178,65 & a & 196,33 & $a b$ \\
\hline D & 40,43 & a & 95,48 & a & 192,65 & b & 211,28 & c \\
\hline $\mathrm{E}$ & 44,70 & a & 97,85 & a & 193,25 & b & 211,83 & $\mathrm{c}$ \\
\hline $\mathrm{F}$ & 45,93 & a & 95,90 & a & 184,28 & $a b$ & 203,38 & $\mathrm{bc}$ \\
\hline G & 52,25 & a & 87,35 & a & 177,73 & a & 195,70 & $a b$ \\
\hline
\end{tabular}

Keterangan : uji rata-rata yang diikuti huruf yang sama pada setiap kolom tidak berbeda nyata berdasarkan Uji Jarak Berganda Duncan pada taraf nyata $5 \%$.

Tabel 2 menunjukkan bahwa semua perlakuan pada periode pengamatan $2 \mathrm{MST}$ dan 4 MST menunjukkan pengaruh yang tidak berbeda nyata. Pada pengamatan 6 MST dan 8 MST perlakuan $D, E$, dan $F$ menunjukkan rata-rata tinggi tanaman yang lebih tinggi dibanding perlakuan lainnya.

\section{2) Diameter Batang}

Data hasil pengamatan ratarata diameter batang tanaman terdapat Tabel 3. 
Tabel 3. Diameter Batang

\begin{tabular}{|c|c|c|c|c|c|c|}
\hline \multirow{2}{*}{ Perlakuan } & \multicolumn{6}{|c|}{ Rata-rata Diameter Batang $(\mathrm{cm})$} \\
\hline & $2 \mathrm{MST}$ & $4 \mathrm{MS}$ & & $6 \mathrm{Mc}$ & & $8 \mathrm{MST}$ \\
\hline A & $1,40 \mathrm{~A}$ & 1,75 & A & 2,15 & a & $2,60 \mathrm{~A}$ \\
\hline B & 1,43 & 1,80 & A & 2,28 & $\mathrm{a}$ & $2,80 \mathrm{abc}$ \\
\hline $\mathrm{C}$ & 1,43 & 1,80 & A & 2,25 & $\mathrm{a}$ & $2,75 \mathrm{ab}$ \\
\hline $\mathrm{D}$ & 1,50 & 1,88 & A & 2,38 & b & $2,98 \mathrm{C}$ \\
\hline $\mathrm{E}$ & 1,53 & 1,80 & A & 2,40 & $\mathrm{~b}$ & $3,00 \mathrm{C}$ \\
\hline $\mathrm{F}$ & 1,38 & 1,83 & A & 2,33 & $a b$ & $2,90 \mathrm{bc}$ \\
\hline G & 1,45 & 1,78 & A & 2,23 & a & $2.73 a b$ \\
\hline
\end{tabular}

Keterangan : Uji rata-rata yang diikuti huruf yang sama pada setiap kolom tidak berbeda nyata berdasarkan Uji Jarak Berganda Duncan pada taraf nyata $5 \%$.

Tabel 3 menunjukkan bahwa semua perlakuan pada periode pengamatan 2 MST dan 4 MST menunjukkan pengaruh yang tidak berbeda nyata. Pada pengamatan 6 MST dan 8 MST perlakuan D menunjukkan rata-rata diameter batang yang lebih besar dibanding perlakuan lainnya.

\section{3) Jumlah Daun per Tanaman}

Data hasil pengamatan ratarata jumlah daun per tanaman terdapat pada Tabel 4. Tabel 4 menunjukkan bahwa semua perlakuan pada periode pengamatan 2 MST dan 4 MST menunjukkan pngaruh yang tidak berbeda nyata. Pada pengamatan 6 MST dan 8 MST perlakuan D menunjukkan rata-rata jumlah daun per tanaman yang lebih banyak dibanding perlakuan lainnya.

Tabel 4. Jumlah Daun per Tanaman

\begin{tabular}{crrrrrr}
\hline \multirow{2}{*}{ Perlakuan } & \multicolumn{5}{c}{ Rata-rata jumlah daun per tanaman (helai) } \\
\cline { 2 - 6 } & $2 \mathrm{MST}$ & $4 \mathrm{MST}$ & $6 \mathrm{MST}$ & $8 \mathrm{MST}$ \\
\hline A & 3,83 & $\mathrm{~A}$ & 7,70 & $\mathrm{~A}$ & $9,30 \mathrm{a}$ & $10,78 \mathrm{a}$ \\
B & 4,13 & $\mathrm{~A}$ & 7,90 & $\mathrm{~A}$ & $10,08 \mathrm{ab}$ & $11,60 \mathrm{abc}$ \\
C & 4,10 & $\mathrm{~A}$ & 7,80 & $\mathrm{~A}$ & $9,70 \mathrm{a}$ & $11,25 \mathrm{ab}$ \\
D & 4,38 & $\mathrm{~A}$ & 8,28 & $\mathrm{~A}$ & $11,18 \mathrm{bc}$ & $12,53 \mathrm{c}$ \\
E & 4,30 & $\mathrm{~A}$ & 8,35 & $\mathrm{~A}$ & $11,25 \mathrm{c}$ & $12,68 \mathrm{C}$ \\
F & 4,00 & $\mathrm{~A}$ & 7,65 & $\mathrm{~A}$ & $11,08 \mathrm{~b}$ & $12,38 \mathrm{bc}$ \\
G & 4,75 & $\mathrm{~A}$ & 7,80 & $\mathrm{~A}$ & $9,70 \mathrm{a}$ & $11,25 \mathrm{ab}$ \\
\hline
\end{tabular}

Keterangan : Uji rata-rata yang diikuti huruf yang sama pada setiap kolom tidak berbeda nyata berdasarkan Uji Jarak Berganda Duncan pada taraf nyata $5 \%$. 
4) Jumlah Tongkol per Tanaman

Data

hasil

pengamatan

rata-rata

jumlah tongkol per tanaman terdapat pada Tabel 5 . Tabel 5 menunjukkan perlakuan komposisi dosis kompos UNPAD dan pupuk buatan menunjukkan pengaruh yang berbeda terhadap jumlah tongkol per tanaman. Perlakuan D menunjukkan rata-rata jumlah tongkol per tanaman yang lebih banyak dibanding perlakuan lainnya.

Tabel 5. Jumlah Tongkol per Tanaman

\begin{tabular}{cc}
\hline Perlakuan & $\begin{array}{c}\text { Rata-rata jumlah } \\
\text { tongkol per } \\
\text { tanaman } \\
\text { (tongkol) }\end{array}$ \\
\hline $\mathrm{A}$ & $1,25 \mathrm{~A}$ \\
$\mathrm{~B}$ & $1,33 \mathrm{Ab}$ \\
$\mathrm{C}$ & $1,28 \mathrm{Ab}$ \\
$\mathrm{D}$ & $1,55 \mathrm{Bc}$ \\
$\mathrm{E}$ & $1,63 \mathrm{C}$ \\
$\mathrm{F}$ & $1,45 \mathrm{Abc}$ \\
$\mathrm{G}$ & $1,28 \mathrm{Ab}$ \\
\hline
\end{tabular}

Keterangan : Uji rata-rata yang diikuti huruf yang sama pada kolom tidak berbeda nyata berdasarkan Uji Jarak Berganda Duncan pada taraf nyata $5 \%$.

\section{5) Panjang Tongkol}

\begin{tabular}{lr}
\multicolumn{1}{c}{ Data } & hasil \\
pengamatan & rata-rata \\
panjang tongkol & terdapat \\
pada Tabel 6. &
\end{tabular}

\begin{tabular}{cc} 
Tabel 6. Panjang Tongkol \\
\hline Pata-rata \\
$\begin{array}{c}\text { Rerlakuan } \\
\text { panjang tongkol } \\
(\mathrm{cm})\end{array}$ \\
\hline $\mathrm{A}$ & $16,60 \mathrm{~A}$ \\
$\mathrm{~B}$ & $17,57 \mathrm{Ab}$ \\
$\mathrm{C}$ & $17,56 \mathrm{Ab}$ \\
$\mathrm{D}$ & $19,56 \mathrm{Bc}$ \\
$\mathrm{E}$ & $20,01 \mathrm{C}$ \\
$\mathrm{F}$ & $17,67 \mathrm{Ab}$ \\
$\mathrm{G}$ & $17,24 \mathrm{~A}$ \\
\hline Keterangan & $:$ Uji rata-rata
\end{tabular} yang diikuti huruf yang sama padakolom tidak berbeda nyata berdasarkan Uji Jarak Berganda Duncan pada taraf nyata $5 \%$

Tabel 6 menunjukkan perlakuan komposisi dosis kompos Unpad dan pupuk buatan menunjukkan pengaruh yang berbeda terhadap panjang tongkol. Perlakuan D menunjukkan rata-rata panjang tongkol yang lebih panjang dibandingkan perlakuan lainnya.

\section{6) Diameter Tongkol}

Data hasil pengamatan rata-rata diameter tongkol terdapat pada Tabel 7. 
Tabel 7. Diameter Tongkol Rata-rata

Perlakuan diameter tongkol $(\mathrm{cm})$

\begin{tabular}{cc}
\hline $\mathrm{A}$ & $4,15 \mathrm{a}$ \\
$\mathrm{B}$ & $4,65 \mathrm{bc}$ \\
$\mathrm{C}$ & $4,63 \mathrm{bc}$ \\
$\mathrm{D}$ & $4,93 \mathrm{c}$ \\
$\mathrm{E}$ & $4,98 \mathrm{c}$ \\
$\mathrm{F}$ & $4,65 \mathrm{bc}$ \\
$\mathrm{G}$ & $4,45 \mathrm{ab}$ \\
\hline Keterangan : Uji rata-rata \\
yang diikuti huruf yang sama \\
padakolom tidak berbeda \\
nyata berdasarkan Uji Jarak \\
Berganda Duncan pada \\
taraf nyata 5\%
\end{tabular}

Tabel 7 menunjukkan perlakuan komposisi dosis kompos Unpad dan pupuk buatan menunjukkan pengaruh yang berbeda terhadap diameter tongkol. Perlakuan D menunjukkan rata-rata diameter tongkol yang lebih besar dibanding perlakuan lainnya.

\section{7)}

\section{Bobot Tongkol Berkelobot}

Data hasil pengamatan rata-rata bobot tongkol berkelobot per tanaman terdapat pada Lampiran 23. Hasil analisisnya disajikan pada Tabel 8.

Tabel 8 menunjukkan perlakuan komposisi dosis kompos UNPAD dan pupuk buatan menunjukkan pengaruh yang berbeda terhadap bobot tongkol berkelobot. Perlakuan D menunjukkan rata-rata bobot tongkol berkelobot yang lebih berat dibanding perlakuan lainnya.

Tabel 8. Bobot Tongkol Berkelobot

\begin{tabular}{cl}
\hline Perlakuan & $\begin{array}{c}\text { Rata-rata bobot } \\
\text { tongkol } \\
\text { berkelobot }(\mathrm{g})\end{array}$ \\
\hline $\mathrm{A}$ & $197,50 \mathrm{a}$ \\
$\mathrm{B}$ & $221,75 \mathrm{ab}$ \\
$\mathrm{C}$ & $215,50 \mathrm{ab}$ \\
$\mathrm{D}$ & $261,25 \mathrm{bc}$ \\
$\mathrm{E}$ & $285,00 \mathrm{c}$ \\
$\mathrm{F}$ & $253,75 \mathrm{bc}$ \\
$\mathrm{G}$ & $201,25 \mathrm{a}$ \\
\hline Keterangan : Uji rata-rata \\
yang diikuti huruf yang sama \\
padakolom tidak berbeda \\
nyata berdasarkan Uji Jarak \\
Berganda Duncan pada \\
taraf nyata 5\%
\end{tabular}

\section{8) Bobot Tongkol Tanpa Kelobot}

Data

hasil

pengamatan rata-rata bobot tongkol tanpa kelobot per tanaman terdapat pada pada Tabel 9.

Tabel 9. Bobot Tongkol Tanpa Kelobot

\begin{tabular}{cc}
\hline Perlakuan & $\begin{array}{c}\text { Rata-rata bobot } \\
\text { tongkol tanpa } \\
\text { kelobot }(\mathrm{g})\end{array}$ \\
\hline $\mathrm{A}$ & $155,00 \mathrm{a}$ \\
$\mathrm{B}$ & $181,50 \mathrm{ab}$ \\
$\mathrm{C}$ & $172,50 \mathrm{ab}$ \\
$\mathrm{D}$ & $211,25 \mathrm{bc}$ \\
$\mathrm{E}$ & $240,00 \mathrm{C}$ \\
$\mathrm{F}$ & $206,25 \mathrm{abc}$ \\
$\mathrm{G}$ & $158,75 \mathrm{ab}$ \\
\hline
\end{tabular}


Keterangan : Uji rata-rata yang diikuti huruf yang sama padakolom tidak berbeda nyata berdasarkan Uji Jarak Berganda Duncan pada taraf nyata $5 \%$

Tabel 9 menunjukkan perlakuan komposisi dosis kompos UNPAD dan pupuk buatan menunjukkan pengaruh yang berbeda terhadap bobot togkol tanpa kelobot. Perlakuan D menunjukkan rata-rata bobot tongkol tanpa kelobot yang lebih berat dibanding perlakuan lainnya.

\section{9) Hasil Tongkol per Plot}

Data hasil pengamatan rata-rata hasil tongkol per plot dapat dilihat pada Tabel 10.

Tabel 10. Hasil Tongkol per Plot

\begin{tabular}{cc}
\hline Perlakuan & $\begin{array}{c}\text { Rata-rata hasil } \\
\text { tongkol per plot } \\
(\mathrm{kg})\end{array}$ \\
\hline $\mathrm{A}$ & $9,68 \mathrm{a}$ \\
$\mathrm{B}$ & $13,38 \mathrm{ab}$ \\
$\mathrm{C}$ & $10,43 \mathrm{a}$ \\
$\mathrm{D}$ & $16,75 \mathrm{~b}$ \\
$\mathrm{E}$ & $17,33 \mathrm{~b}$ \\
$\mathrm{~F}$ & $15,93 \mathrm{~b}$ \\
$\mathrm{G}$ & $10,35 \mathrm{a}$ \\
\hline Keterangan : Uji rata-rata \\
yang diikuti huruf yang sama \\
padakolom tidak berbeda \\
nyata berdasarkan Uji Jarak \\
Berganda Duncan pada \\
taraf nyata 5\%
\end{tabular}

Tabel 10 menunjukkan perlakuan komposisi dosis kompos UNPAD dan pupuk buatan menunjukkan pengaruh yang berbeda terhadap bobot tongkol per plot. Perlakuan D, E, dan F menunjukkan rata-rata bobot tongkol per petak yang lebih berat dibanding perlakuan lainnya.

\section{0) Indeks Panen}

Data

hasil pengamatan rata-rata indeks panen terdapat pada Tabel 11.

Tabel 11. Indeks Panen

\begin{tabular}{cc}
\hline Perlakuan & $\begin{array}{c}\text { Rata-rata indeks } \\
\text { panen (\%) }\end{array}$ \\
\hline $\mathrm{A}$ & $78,53 \mathrm{~A}$ \\
$\mathrm{~B}$ & $80,22 \mathrm{~A}$ \\
$\mathrm{C}$ & $79,83 \mathrm{~A}$ \\
$\mathrm{D}$ & $80,64 \mathrm{~A}$ \\
$\mathrm{E}$ & $83,99 \mathrm{~A}$ \\
$\mathrm{~F}$ & $80,56 \mathrm{~A}$ \\
$\mathrm{G}$ & $78,57 \mathrm{~A}$ \\
\hline Keterangan : Uji rata-rata \\
yang diikuti huruf sama \\
padakolom yang sama tidak \\
berbeda nyata berdasarkan \\
Uji Jarak Berganda Duncan \\
pada taraf nyata 5\% \\
\multicolumn{4}{c}{ Tabel 11 menunjukkan } \\
perlakuan komposisi dosis \\
kompos Unpad dan pupuk \\
buatan tidak menunjukkan \\
pengaruh yang berbeda \\
terhadap indeks panen, \\
meskipun tidak berbeda \\
nyata perlakuan $\mathrm{E}$ \\
menunjukkan rata-rata
\end{tabular}


indeks panen yang lebih tinggi dibanding perlakuan lainnya.

\section{KESIMPULAN}

1) Komposisi dosis kompos Unpad dan pupuk buatan berpengaruh terhadap pertumbuhan dan hasil jagung manis (Zea mays saccharata I.) varietas Bonanza.

2) Komposisi dosis perlakuan 4 ton kompos/ha $+5 \mathrm{cc} / \mathrm{POC}$ $+180 \mathrm{~kg}$ Urea/ha, $60 \mathrm{~kg}$ SP-36/ha, $60 \mathrm{~kg} \mathrm{KCl} / \mathrm{ha} 3$ berpengaruh paling baik terhadap tinggi tanaman, diameter batang, jumlah daun per tanaman, panjang tongkol, diameter tongkol, bobot tongkol berkelobot, bobot tongkol tanpa kelobot, dan hasil tongkol per plot.

\section{DAFTAR PUSTAKA}

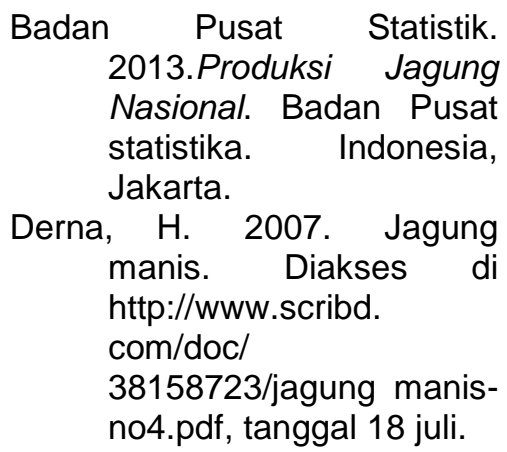

